Original Research Article

\title{
A comparative study of efficacy and safety of tamsulosin with nifedipine versus tamsulosin alone as medical expulsive therapy for lower ureteric stones
}

\author{
Arun Suresh ${ }^{1}$, Narendranath Sanji ${ }^{2}$, Naveen Hebbal Nagarajappa ${ }^{3}$, \\ Shashikala Gowdara Hanumanthareddy ${ }^{2}$, Pallavi Mahadeva Kamath ${ }^{1}$
}

\begin{abstract}
${ }^{1}$ Senior Drug Safety Physician Bioclinica, Mysuru, Karnataka, India

${ }^{2}$ Department of Pharmacology,

${ }^{3}$ Department of Urology, JJM

Medical College, Davanagere, Karnataka, India
\end{abstract}

Received: 28 July 2019

Revised: 18 September 2019

Accepted: 19 September 2019

\section{*Correspondence to:}

Dr. Narendranath Sanji,

Email: sanji_naren@yahoo.com

Copyright: (C) the author(s), publisher and licensee Medip Academy. This is an openaccess article distributed under the terms of the Creative Commons Attribution NonCommercial License, which permits unrestricted noncommercial use, distribution, and reproduction in any medium, provided the original work is properly cited.

\begin{abstract}
Background: Lower ureteric stones (LUS) comprises of $70 \%$ of ureteric stones. Spontaneous passage depends on stone size and location in ureter. Impacted calculi initiate smooth muscles contractions causing ureteric spasms. $\alpha-1$ blockers like tamsulosin and calcium channel blocker like nifedipine relaxes ureteric smooth muscle, facilitating spontaneous expulsion. Pain and discomfort associated with urolithiasis, hospitalization and surgical cost can be minimized by medical expulsive therapy. Many studies had compared efficacy of tamsulosin with nifedipine, only few have explored the combination. This study compared efficacy of nifedipine and tamsulosin versus tamsulosin alone.

Methods: 64 patients with LUS $(5-10 \mathrm{~mm})$ were assigned into 2 groups. Group 1 received tamsulosin and nifedipine and group 2 only tamsulosin. Rate of expulsion, time to expulsion, analgesic frequency and pain VAS score were analyzed. Chi-square or Fisher's exact test to analyze categorical data, Mann Whitney $U$ test or unpaired t test for differences between groups and Wilcoxon matched-pairs signed rank test for within group. A $p<0.05$ was statistically significant.

Results: Rate of expulsion was $87.5 \%$ in group 1 and $65.6 \%$ in group 2 $(\mathrm{p}<0.05)$. Mean expulsion time was $6.68 \pm 1.89$ days for group 1 and $8.52 \pm 2.62$ in group $2(\mathrm{p}<0.05)$. Analgesic requirement was similar. Adverse effects were headache, dizziness and postural hypotension.

Conclusions: Combination therapy yielded better rate of expulsion and reduction in stone expulsion time than tamsulosin alone. Thus, combination therapy can be considered for effective treatment outcomes.
\end{abstract}

Keywords: Lower ureteric stones, Medical expulsive therapy, Tamsulosin, Nifedipine

\section{INTRODUCTION}

Urolithiasis is a chronic disease affecting $8-15 \%$ of the world population. ${ }^{1}$ The risk of developing urolithiasis among adults is higher in the western countries like Europe (5-9\%), Canada (12\%), USA (13-15\%) than that in the eastern hemisphere. However, some of the Asian countries like Saudi Arabia have reported highest risk of $20.1 \%$. $^{2}$ Urolithiasis is associated with a higher risk of recurrence after initial episode. This risk is estimated to be $50 \%$ at 5 years and $70 \%$ at 9 years. ${ }^{3}$
The incidence of urolithiasis in a given population is influenced by geographical area, racial distribution and socioeconomic status. The changes in dietary habits as well as socioeconomic factors have influenced not only the incidence but also the composition of the stone. ${ }^{2}$ Renoureteral calculus composed of calcium oxalate and phosphate is encountered more commonly in economically developed countries where as those of ammonium urate and calcium oxalate is frequent in Asian countries. India comes in the Afro-Asian stone forming belt and urolithiasis affects all age groups ranging from 
less than a year to more than 70 years with a male: female ratio of $2: 1 .^{2}$

Prevalence of urolithiasis in India ranges from $4-20 \%{ }^{2}$ Stone recurrence rate is also higher in countries with warm or hot climates where low urinary output and scanty water intake are probable causes. ${ }^{2}$ Ureteric stones invariably originate from kidneys and on its course from renal pelvis to bladder, gets impacted in any of the anatomical narrowings. ${ }^{4}$ Ureteric stones account for approximately $20 \%$ of urolithiasis cases. Of this approximately $70 \%$ are located in the lower one third of the ureter. ${ }^{5}$

Hypercalciuria is still the most common underlying factor for urolithiasis of calcium oxalate type worldwide. On the other hand, hypocitraturia is the leading cause in some eastern countries. Hyperuricosuria and hyperoxaluria are less frequently encountered metabolic risk factors. Struvite or infection related stones are rarely seen nowadays in developed countries. ${ }^{2}$

The likelihood and time to spontaneous expulsion of stones mainly depends on size of the stone and its location in the ureter. ${ }^{6}$ According to the results of a metaanalysis published by American Urological Association, $98 \%$ of ureteric calculi having size less than $5 \mathrm{~mm}$ in diameter is likely to pass spontaneously without any intervention and requires only observation and symptomatic treatment. ${ }^{7}$ Stones up to $6 \mathrm{~mm}$ might require 42 days for spontaneous expulsion. They can be managed conservatively using pharmacological intervention to control pain, ureteric spasm, edema and infection, thus hastening and facilitating stone expulsion.,

The current treatment modalities for lower ureteric stones (LUS) comprises of conservative and surgical management. Conservative management consists of wait and watch approach or spontaneous expulsion and the other being medical expulsive therapy (MET). Various drugs used in MET are: alpha-1 blocker like tamsulosin, a calcium channel blocker nifedipine, corticosteroids and recently phosphodiesterase 5 (PDE5) inhibitors. Rationale for using corticosteroids is to alleviate oedema caused by mucosal reaction triggered by the presence of ureteric stone whereas PDE5 inhibitors increases cGMP causing smooth muscle relaxation in ureters. ${ }^{8}$ The Surgical management recommended for active stone removal is shock wave lithotripsy (SWL) or ureteroscopy (URS). ${ }^{9}$ SWL is the most widely used treatment modality for the management of both ureteric and renal stones. ${ }^{10}$ The surgical management by means of minimally invasive procedures like SWL and URS have their own measurable risks and are expensive. ${ }^{1}$ The European Urology Association and American Urological Association (EUA/AUA) 2007 guidelines suggest tamsulosin and nifedipine as reasonable treatment choices for MET. ${ }^{9,11}$ However they state that there is insufficient evidence to recommend regular use of corticosteroids or PDE5 inhibitors as monotherapy. ${ }^{8}$ Adverse effects associated with long term treatment with corticosteroids makes it an unsuitable candidate for MET. ${ }^{12}$ Alpha-1 adrenergic receptor blockers like tamsulosin $\left(\alpha_{1 \mathrm{~A}} / \alpha_{1 \mathrm{D}}\right)$ and nifedipine a calcium channel blocker are known to cause relaxation of ureteric smooth muscles, thereby enhancing the spontaneous passage of LUS and are extensively used in MET. ${ }^{9,11}$ MET with active monitoring is a valid option for stone sizes up to $10 \mathrm{~mm}$ especially for distal ureteric calculus. ${ }^{10}$ This approach can be a cost-effective strategy before opting for active stone removal. ${ }^{1,10}$

Studies have revealed the presence of $\alpha_{1}$ adrenergic receptors in ureter with highest density in lower ureters. ${ }^{10}$ $\alpha_{1}$ adrenergic antagonists have demonstrated to inhibit basal tone, peristaltic frequency, and ureteric contractions intramurally. ${ }^{13}$ This results in increased fluid transport and decrease in intra-ureteric pressure. ${ }^{12}$ Recent studies including a meta-analysis and a Cochrane systematic review have reported excellent reports on tamsulosin in terms of control of colic as well as expulsion of distal ureteric calculus. $^{8,13,14}$ In addition to this visceral referred pain is blocked by acting on group C-fibers or sympathetic postganglionic neurons. ${ }^{8,12}$

Generation of action potential and subsequent contraction of ureter requires $\mathrm{Ca}^{2+}$. Nifedipine is a dihydropyridine class of L-type calcium channel blocker that can block the movement of $\mathrm{Ca}^{2+}$ in the cell and is expected to depress ureteric function through its spasmolytic effect. Nifedipine modifies the effect of calcium on ureteric smooth muscles there by decreasing the ureteric contractions and subsequently ureteric colic. ${ }^{12}$ The rationale for the use of combination is that the alphablockers being predominant in lower ureter, is more effective for distal or LUS whereas calcium channel blocker acts along the entire length of ureter. Both the drugs might work in synergy to reduce the force of ureteric spasm, in turn increasing the hydrostatic pressure, proximal to the stone and relaxing the ureter both at the site of the calculus and distal to it, thus causing expulsion of stone. ${ }^{15}$

Urolithiasis has significant economic consequences and is a great burden on public health. ${ }^{16}$ Thus, a non-invasive medical expulsion of ureteric stone can avoid surgical procedures, their associated cost, risks and also increasing its efficacy by supplementing it at times. ${ }^{1,17}$ In the present study the aim was to evaluate the efficacy and safety of a combination of tamsulosin and nifedipine with that of tamsulosin alone as MET in LUS.

\section{METHODS}

This randomized open label prospective study was conducted in patients with LUS visiting Urology Outpatient Department (OPD) of Bapuji Hospital and Chigateri General Hospital attached to JJM Medical College, Davanagere between November 2014 to July 2016. Institutional Ethical Committee clearance was obtained prior to conducting the study. 
Both male and female patients' $\geq 18$ years of age who are diagnosed with LUS of 5-10 mm diameter by ultrasound abdomen pelvis or NCCT with or without X-ray KUB were included in study. The other inclusion criteria were: patients presenting with acute renal colic for the first time, multiple ureteric stones, unilateral and bilateral ureteric stone. Pregnant, breastfeeding women, gross hydronephrosis, known hypersensitivity to tamsulosin or nifedipine, stone in ureter draining a solitary kidney (anatomically or functionally), patients with abnormal renal tract anatomy (duplex system, horseshoe kidney), chronic kidney disease stage 4 or stage 5 (estimated glomerular filtration rate $<30 \mathrm{ml} / \mathrm{min}$ ) or patients on dialysis, patients concurrently taking alpha blockers, calcium channel blocker or PDE-5 inhibitors, previous history of ureteric manipulations and/or surgery or presence of ureteric stricture were excluded from the study. Prevalence of nephrolithiasis in India is $4-20 \%{ }^{2}$ Out of which $20 \%$ are ureteric stone cases and $70 \%$ of this are LUS cases. ${ }^{5}$ Hence the prevalence of LUS in India is estimated to be $1.68 \%$. OpenEpi, a standard software was used to calculate sample size at $97 \%$ confidence level and an absolute precision of $5 \%$ with a prevalence of $1.68 \% .{ }^{18}$ The sample size was estimated to be 32 subjects in each group. Hence a total of 64 patients were enrolled in the study.

A total of 64 patients satisfying the inclusion criteria were randomly assigned in the ratio of 1:1 to either of the two groups. Written informed consent was taken from all study subjects after explaining the study details in the language patient comprehends. Group 1 received both cap tamsulosin $0.4 \mathrm{mg}$ OD p.o and tab nifedipine $10 \mathrm{mg}$ sustained release (SR) OD p.o. both at bed time (HS). Whereas Group 2 received only cap tamsulosin $0.4 \mathrm{mg}$ OD p.o. (HS). All patients were prescribed a combination of tab drotaverine $80 \mathrm{mg}$ and mefenamic acid $250 \mathrm{mg}$ BD p.o and patients were asked to take them for pain if required. They were instructed to note down and report the number of days of requirement of analgesic. The treatment duration in each patient was till the expulsion of stone or 28 days, whichever was earlier. The patients were advised to drink plenty of water $(\geq 21 /$ day) and to use a sieve while voiding the urine to highlight the stone expulsion. ${ }^{1}$ On the event of stone expulsion or at 28 days, which ever was earlier (end of treatment), they were required to visit the urology $\mathrm{OPD}$, where radiological investigations were done to confirm stone expulsion. The stone expulsion rate, stone expulsion time, analgesic frequency and visual analog scale (VAS) score were assessed for both the groups as efficacy parameters. At baseline, if the pain experienced by the patient was intolerable, $75 \mathrm{mg}$ of Inj. diclofenac was administered intramuscularly. Pain assessment was made not only on basis of frequency of analgesic used but also by analysing its intensity using VAS score done at baseline and at the end of treatment. Additional investigations like urine analysis, culture and or sensitivity were done as and when needed. In cases of failure of stone expulsion up till day
28 , or intolerable pain and signs of infection on urine analysis, patients were instructed to present themselves to the Bapuji Hospital Causality for prompt intervention. Depending on the evaluation, emergency management by J-stenting or emergency or elective SWL or URS will be planned by the Urologist.

Efficacy parameters were expulsion rate i.e. whether the stone was expelled or not, expulsion time i.e. if the stone was expelled, the time to expulsion from the commencement of therapy. The pain scoring was also analysed using VAS before and after treatment. Safety assessment was based on treatment-emergent adverse effects and changes in vital signs with emphasis on blood pressure. The intensity of pain was estimated using the VAS score, both at baseline and at the end of treatment. Visual analog scale is ideal for the subjective assessment of intensity of pain in patients and is used routinely in its clinical assessment. ${ }^{19}$ It has a scale of 0 to 10 where 0 indicates no pain and 10 indicate worst pain imaginable. ${ }^{19}$ Patients were requested to define pain experienced by them on VAS scale of 0 to 10 by comparing it with the most severe pain the patients could imagine.

\section{Statistical analysis}

Expulsion rate of both the groups were compared using Chi-square test. Time to expulsion and frequency of analgesic of both the groups were analyzed using Student's unpaired t-test. VAS score at baseline and at the end of therapy were assessed using Mann Whitney U test. For comparison of VAS score between the two groups, Wilcoxon matched-pairs signed rank test was used. Adverse effects of both the groups were analyzed using Fisher's exact test.

\section{RESULTS}

All the 64 patients enrolled completed the study. The baseline characteristics in both groups with respect to age, gender, stone size, laterality of stone, need for diclofenac IM injection or VAS score assessed at baseline were similar (Table 1).

The mean size of ureteric calculus in group 1 was $6.47 \pm 0.92$ and that of group 2 was $6.12 \pm 0.98$ (Table 2). Stone expulsion occurred successfully in 28 out of 32 patients $(87.5 \%)$ in group 1 . On the other hand, 21 out of 32 patients $(65.6 \%)$ showed a positive stone expulsion in group 2. This combination of tamsulosin and nifedipine had a higher rate of stone expulsion than tamsulosin alone, which was statistically significant with a $\mathrm{p}$ value of 0.039 (Table 3). As shown in Table 4, the mean time taken in those who expelled the stones was lower $(6.68 \pm 1.89)$ in group 1 than $(8.52 \pm 2.62)$ in group 2 $(p=0.0062)$. The frequency of analgesic use in both the groups were similar and the combination did not show any statistically significant reduction in the analgesic use compared to tamsulosin alone ( $\mathrm{p}=0.3)$ (Table 5 and 6). 
Table 1: Baseline characteristics of the patients.

\begin{tabular}{|c|c|c|c|}
\hline \multirow[t]{2}{*}{ Variables } & $\begin{array}{l}\text { Group } 1 \text { (tamsulosin and } \\
\text { nifedipine) }(\mathrm{n}=32)\end{array}$ & $\begin{array}{l}\text { Group } 2 \text { (tamsulosin) } \\
(\mathbf{n}=32)\end{array}$ & \multirow[t]{2}{*}{$P$ value } \\
\hline & $\mathbf{N}(\%)$ & $\mathbf{N}(\%)$ & \\
\hline Mean age (years) $($ mean \pm SD $)$ & $34.8 \pm 11.1$ & $32.47 \pm 10.3$ & 0.39 \\
\hline \multicolumn{4}{|l|}{ Gender } \\
\hline Male & $24(75)$ & $26(81.3)$ & \multirow{2}{*}{0.55} \\
\hline Female & $8(25)$ & $6(18.8)$ & \\
\hline Stone size $(\mathrm{mm})($ mean \pm SD $)$ & $6.47 \pm 0.92$ & $6.12 \pm 0.98$ & 0.15 \\
\hline \multicolumn{4}{|l|}{ Laterality } \\
\hline Left & $20(62.5)$ & $21(65.6)$ & \multirow{2}{*}{0.80} \\
\hline Right & $12(37.5)$ & $11(34.4)$ & \\
\hline VAS score $(0$ week $)($ mean \pm SD $)$ & $5 \pm 0.84$ & $4.94 \pm 1.0$ & 0.39 \\
\hline \multicolumn{4}{|c|}{ Inj. diclofenac $75 \mathrm{mg}$ IM at first visit } \\
\hline $\mathrm{N}$ & 4 & 4 & \multirow{2}{*}{$>0.999$} \\
\hline Mean \pm SD & $0.13 \pm 0.34$ & $0.13 \pm 0.34$ & \\
\hline
\end{tabular}

Table 2: Size of stone in both the groups.

\begin{tabular}{|lllll|}
\hline Group & N & $\begin{array}{l}\text { Size of stone }(\mathrm{mm}) \\
\text { Mean } \pm \text { SD }\end{array}$ & SEM & \\
\hline Group 1 & 32 & $6.47 \pm 0.92$ & 0.16 & P $=0.1485$ \\
\hline Group 2 & 32 & $6.12 \pm 0.98$ & 0.17 & NS \\
\hline
\end{tabular}

SD: standard deviation; SEM: standard error of mean; NS: not significant ( $p>0.05)$.

Table 3: Expulsion rate in both the groups.

\begin{tabular}{|llll|}
\hline Expulsion & Groups & Total & \\
\hline Yes & Group 1 N (\%) & Group 2 N (\%) & 49 \\
\hline No & $28(87.5)$ & $21(65.6)$ & P $=0.039$ \\
\hline Total & $4(12.5)$ & $11(34.4)$ & 15 \\
\hline
\end{tabular}

$\chi^{2}=4.27, \mathrm{p}<0.05$.

Table 4: Time to stone expulsion in both the groups.

\begin{tabular}{lllllll}
\hline & Group & N & Mean (in days) & SD & SEM \\
$\begin{array}{llllll}\text { Stone expelled } \\
\text { (yes) }\end{array}$ & $\begin{array}{l}\text { Group 1 (tamsulosin } \\
\text { and nifedipine) }\end{array}$ & 28 & 6.68 & 1.89 & $0.36 \quad t$ & $\mathrm{t}=2.868$ \\
& Group 2 (tamsulosin) & 21 & 8.52 & 2.62 & 0.57 & $\mathrm{P}=0.0062$ \\
\hline
\end{tabular}

SD: standard deviation; SEM: standard error of mean; $\mathrm{p}<0.05$.

Table 5: Frequency of analgesic requirement in both the groups.

\begin{tabular}{|c|c|c|c|c|}
\hline Group & Mean no of days & SD & SEM & \\
\hline 1 & 3.28 & 0.46 & 0.08 & $\mathrm{t}=1.05$ \\
\hline 2 & 3.41 & 0.50 & 0.09 & $\mathrm{P}=0.3 \mathrm{NS}$ \\
\hline
\end{tabular}

Table 6: VAS score before and after treatment.

\begin{tabular}{|c|c|c|c|}
\hline \multirow{2}{*}{ VAS score } & \multicolumn{2}{|c|}{ Treatment group } & \multirow{2}{*}{ P value } \\
\hline & Group 1 & Group 2 & \\
\hline Baseline score (0 week) & $5 \pm 0.8$ & $4.94 \pm 1.0$ & 0.93 \\
\hline End of treatment (4 weeks) & $0.5 \pm 1.3$ & $1.06 \pm 1.5$ & 0.08 \\
\hline Difference within group $p$ value & $<0.001$ & $<0.001$ & \\
\hline
\end{tabular}


Table 7: Adverse effects of the study groups.

\begin{tabular}{|c|c|c|c|c|}
\hline Adverse effects & $\begin{array}{l}\text { Tamsulosin and nifedipine } \\
\text { (Group 1) }\end{array}$ & $\begin{array}{l}\text { Tamsulosin } \\
\text { (Group 2) }\end{array}$ & Total & $P$ value \\
\hline Headache & 1 & 1 & 2 & \multirow{4}{*}{1.0} \\
\hline Postural hypotension & 1 & 0 & 1 & \\
\hline Dizziness & 1 & 1 & 2 & \\
\hline Total & 3 & 2 & 5 & \\
\hline
\end{tabular}

Three patients in group 1 reported adverse effects $(9.38 \%)$ as shown in Table 7 which included headache, postural hypotension and dizziness. Two in group 2 reported adverse effects $(6.25 \%)$ of headache and dizziness. Fisher's exact test was applied and $\mathrm{p}$ value of 1.0 was obtained, which was not statistically significant. These adverse effects were mild and self-limiting and did not warrant patient withdrawal from the study. For instance, postural hypotension with tamsulosin was seen only initially and was not reported later.

\section{DISCUSSION}

Ureteric stones are a commonly encountered problem in emergency department practice. ${ }^{12}$ Prevalence of urolithiasis in India ranges from 4-20\% with a male: female ratio of $2: 1{ }^{2}$ Ureteric stones account for approximately $20 \%$ of urolithiasis cases, out of which $70 \%$ are located in the lower one third of the ureter. ${ }^{3}$ About $50 \%$ of the patients will have recurrence within 5 years of first episode. ${ }^{3,8}$ The likelihood and time to spontaneous expulsion of stones depends on factors like size of the stone, its location in the ureter and ureteric muscle spasm. ${ }^{6,8,12}$ Stones up to $6 \mathrm{~mm}$ might require 42 days for spontaneous expulsion. In the absence of uncontrolled pain, inadequate renal function, clinical evidence for sepsis (indications for immediate intervention), they can be managed conservatively using pharmacological intervention to control pain, ureteric spasm, edema and infection thus facilitating and accelerating stone expulsion. ${ }^{1,7,12}$ MET with active monitoring is a valid option for stones up to $10 \mathrm{~mm}$ especially for distal ureteric calculus. ${ }^{10}$ This approach can be a cost-effective strategy before opting for active stone removal. The EUA/AUA 2007 guidelines suggest tamsulosin and nifedipine for MET. ${ }^{11}$ Urolithiasis has significant economic consequences and is a great burden on public health. ${ }^{16}$ Even though minimally invasive procedures such as extracorporeal shock wave lithotripsy, ureterorenoscopy are effective, they are not without risks and are expensive. MET can circumvent this for stones up to $10 \mathrm{~mm}$ by potentially preventing hospitalization for treatment, cutting risks, and being cost saving. ${ }^{12,17}$ In this randomized open label prospective clinical study, a combination of tamsulosin and nifedipine was compared with a monotherapy of tamsulosin to assess its efficacy and safety as MET in LUS of size 5 to $10 \mathrm{~mm}$ diameter.

The rate of stone expulsion of combination was found to be higher than tamsulosin monotherapy $(87.5 \%$ vs
$65.6 \%$ ). There was a statistically significant increase in rate of stone expulsion with the combination therapy $(\mathrm{p}=0.039)$. The mean time to expulsion of ureteric stones for the combination was $6.68 \pm 1.89$ which was less than that of monotherapy with tamsulosin 8.52 \pm 2.62 $(\mathrm{p}=0.0062)$. In a study conducted by Gandhi et al, tamsulosin monotherapy yielded stone expulsion rate of $79.7 \%$ and mean time to expulsion of 9 days where as nifedipine monotherapy yielded an expulsion rate of $55.2 \%$ and mean time to expulsion of 23 days. ${ }^{1}$ The EUA/AUA guidelines recommend tamsulosin as the first line therapy for MET especially in distal ureteric stones and in patients with no role for immediate surgical removal. ${ }^{8,11}$ Nifedipine is the only calcium channel blocker that has been revealed to be beneficial in stone expulsion. It is effective in renal colic although improvement in stone expulsion rate has been minimal. Therefore, most recent EAU guidelines do not recommend monotherapy of nifedipine as MET. However, it is said that it can be safely used concurrently with alpha blockers in appropriate patient population as the side effects have been noted to be insignificant. ${ }^{8}$ The frequency of analgesic use was comparable in both the groups $(p=0.3001)$ and the combination did not demonstrate statistically significant reduction in analgesic use compared to tamsulosin alone. This result was similar to the study by Maitra et al, where the combination did not show a statistically significant difference in terms of decrease in episodes of ureteric colic and requirement of analgesic and or antispasmodic. ${ }^{15}$ In group 1 , three patients out of 32 reported adverse effects $(9.375 \%)$ in which one had headache, other had symptoms suggestive of postural hypotension and one complained of dizziness. In group 2 two out of 32 patients reported adverse effects $(6.25 \%)$. One reported headache and the other complained of dizziness. These adverse effects were mild, comparable in both the groups and none of the patients withdrew from the study because of them.

\section{CONCLUSION}

The results of this study demonstrate superiority of the combination over monotherapy. The combination of tamsulosin with nifedipine had a statistically significant, higher rate of expulsion and reduction in duration to expulsion than tamsulosin monotherapy. Usually surgical intervention such as SWL and URS are considered for ureteric stone sizes above $5 \mathrm{~mm}$ diameter, but what this study has demonstrated is that the combination could effectively be used as MET for LUS of 5 to $10 \mathrm{~mm}$, thus 
broadening the role of pharmacotherapy. The combination also demonstrated that it can potentially reduce the treatment duration of MET. With treatment emergent adverse effects comparable to tamsulosin monotherapy, the combination proves to be a safe and efficacious alternative to SWL or URS for ureteric stones up to 10 $\mathrm{mm}$. The positive results of this study warrant additional large-scale trials with combination especially considering a lack of similar studies.

The combination of tamsulosin and nifedipine can be considered over monotherapy with tamsulosin in patients as MET for LUS of 5 to $10 \mathrm{~mm}$ who are amenable to waiting management. This along with active monitoring periodically, further ensures a safe and optimal therapy for LUS up to a size of $10 \mathrm{~mm}$ by offering a higher rate of stone expulsion, shorter time for expulsion, less need for analgesic, preventing hospitalization and being a risk free and cost-effective alternative.

\section{ACKNOWLEDGEMENTS}

My sincere gratitude to department of Medicine JJM Medical College. I would like to thank Central Lab JJM Medical college and the subjects of this study for their cooperation.

Funding: No funding sources

Conflict of interest: None declared

Ethical approval: The study was approved by the Institutional Ethics Committee

\section{REFERENCES}

1. Gandhi HR, Agarwal C. The efficacy of tamsulosin vs. nifedipine for the medical expulsive therapy of distal ureteric stones: a randomised clinical trial. Arab J Urol. 2013;11(4):405-10.

2. Lopez M, Hoppe B. History, epidemiology and regional diversities of urolithiasis. Pediatr Nephrol. 2010;25(1):49-59.

3. Barnela SR, Soni SS, Saboo SS, Bhansali AS. Medical management of renal stone. Indian $\mathrm{J}$ Endocrinol Metab. 2012;16(2):236-9.

4. Roy H. Short textbook of surgery: with focus on clinical skills. Delhi: Jaypee Medical Publishers; 2011: 292.

5. Yuksel M, Yilmaz S, Tokqoz H, Yalcinkaya S, Bas $\mathrm{S}$, Ipekci $\mathrm{T}$, et al. Efficacy of silodosin in the treatment of distal ureteral stones 4 to $10 \mathrm{~mm}$ in diameter. Int J Clin Exp Med. 2015;8(10):19086-92.

6. Coll DM, Varanelli MJ, Smith RC. Relationship of spontaneous passage of ureteral calculi to stone size and location as revealed by unenhanced helical CT. Am J Roentgenol. 2002;178(1):101-3.
7. Segura JW, Preminger GM, Assimos DG, Dretler SP, Kahn RI, Lingeman JE, et al. Ureteral Stones Clinical Guidelines Panel summary report on the management of ureteral calculi. The American Urological Association. J Urol. 1997;158(5):1915-21.

8. Bos D, Kapoor A. Update on medical expulsive therapy for distal ureteral stones: Beyond alphablockers. Can Urol Assoc J. 2014;8(11-12):442-5.

9. Turk C, Knoll T, Petrik A, Sarica K, Skolarikos A, Straub M, et al. EAU Guidelines on Interventional Treatment for Urolithiasis. Eur Urol. 2016;69(3):47582.

10. Osorio L, Lima E, Auttorino R, Marcelo F. Emergency management of ureteral stones:Recent advances. Indian J Urol. 2008;24(4):461-6.

11. Preminger GM, Tiselius HG, Assimos DG, Alken P, Buck C, Galluci M, et al. 2007 guideline for the management of ureteral calculi. $\mathrm{J}$ Urol. 2007;178(6):2418-34.

12. Picozzi SC, Marenghi C, Casellato S, Ricci C, Gaeta M, Carmignani L. Management of ureteral calculi and medical expulsive therapy in emergency departments. J Emerg Trauma Shock. 2011;4(1):706.

13. Fan B, Yang D, Wang J, Che X, Li X, Wang L et al. Can tamsulosin facilitate expulsion of ureteral stones? A meta-analysis of randomized controlled trials. Int J Urol. 2013;20(8):818-30.

14. Campschroer T, Zhu Y, Duijvesz D, Grobbee DE, Lock MT. Alpha-blockers as medical expulsive therapy for ureteral stones. Cochrane Database Syst Rev. 2018;4:CD008509.

15. Maitra T. Prospective randomized trial comparing the efficacy of tamsulosin and tamsulosin combined with nifedipine for the management of lower ureteral stones. Turk J Urol. 2012;38(1):32-5.

16. Turney BW, Reynard JM, Noble JG, Keoghane SR. Trends in urological stone disease. BJU Int. 2012;109(7):1082-7.

17. Griwan MS, Singh SK, Paul H, Pawar DS, Verma M. The efficacy of tamsulosin in lower ureteral calculi. Urol Ann. 2010;2(2):63-6.

18. Sullivan KM, Dean A, Soe MM. OpenEpi: A webbased epidemiological and statistical calculator for public health. Public Health Rep. 2009;124(3):471-4.

19. Breivik H, Borchgrevink PC, Allen SM, Rosseland LA, Romundstad L, Hals EK. Assessment of pain. Br J Anaesth. 2008;101(1):17-24.

Cite this article as: Suresh A, Sanji N, Nagarajappa NH, Hanumanthareddy SG, Kamath PM. A comparative study of efficacy and safety of tamsulosin with nifedipine versus tamsulosin alone as medical expulsive therapy for lower ureteric stones. Int J Basic Clin Pharmacol 2019;8:2278-83. 